\title{
Defining nicotine dependence for genetic research: evidence from Australian twins
}

\author{
CHRISTINA N. LESSOV*, NICHOLAS G. MARTIN, DIXIE J. STATHAM, \\ ALEXANDRE A. TODOROV, WENDY S. SLUTSKE, KATHLEEN K. BUCHOLZ, \\ ANDREW C. HEATH AND PAMELA A. F. MADDEN \\ Department of Psychiatry, Washington University School of Medicine, St Louis, MO, USA; University of \\ Missouri, Columbia, MO, USA; Queensland Institute of Medical Research, Brisbane, Australia
}

\begin{abstract}
Background. Whether current criteria used to define nicotine dependence are informative for genetic research is an important empirical question. The authors used items of the DSM-IV and of the Heaviness of Smoking Index to characterize the nicotine dependence phenotype and to identify salient symptoms in a genetically informative community sample of Australian young adult female and male twins.
\end{abstract}

Method. Phenotypic and genetic factor analyses were performed on nine dependence symptoms (the seven DSM-IV substance dependence criteria and the two Heaviness of Smoking Index (HSI) items derived from the Fagerström Tolerance Questionnaire, time to first cigarette in the morning and number of cigarettes smoked per day). Phenotypic and genetic analyses were restricted to ever smokers.

Results. Phenotypic nicotine dependence symptom covariation was best captured by two factors with a similar pattern of factor loadings for women and men. In genetic factor analysis item covariation was best captured by two genetic but one shared environmental factor for both women and men; however, item factor loadings differed by gender. All nicotine dependence symptoms were substantially heritable, except for the DSM-IV criterion of 'giving up or reducing important activities in order to smoke', which was weakly familial.

Conclusions. The salient behavioral indices of nicotine dependence are similar for women and men. DSM-IV criteria of tolerance, withdrawal, and experiencing difficulty quitting and HSI items time to first cigarette in the morning and number of cigarettes smoked per day may represent the most highly heritable symptoms of nicotine dependence for both women and men.

\section{INTRODUCTION}

Nicotine is a psychoactive substance and dependence on nicotine is recognized as a mental disorder (APA, 1994). Despite the enormous public health problem and cost associated with smoking (CDC, 2002) and the tremendous addictive potential of smoking (Stolerman \& Jarvis, 1995; Henningfield \& Jude, 1999; Dani

\footnotetext{
* Address for correspondence: Dr Christina N. Lessov, SRI International, Center for Health Sciences, 333 Ravenswood Ave, BN116, Menlo Park, CA 94025, USA.

(Email: Christina.lessov@sri.com)
}

et al. 2001), empirical evidence about the validity of current criteria used to define nicotine dependence is scant.

Although the harmful effects of smoking were first described in the 1964 Surgeon General report (USDHHS, 2000), tobacco-related research has surged only in the past decade (Swan, 1999). Clinically, nicotine dependence is most often defined using the seven dependence criteria of the DSM-IV, the eight-item Fagerström Tolerance Questionnaire (FTQ; Fagerström, 1978), and its modified six-item version, the Fagerström Test for Nicotine Dependence (FTND; Heatherton 
et al. 1991). The DSM-IV dependence criteria are applied to a wide range of substances (Cottler et al. 1995). With the exception of nicotinespecific withdrawal symptoms described in the DSM-IV, the degree to which each DSM-IV substance dependence criterion is appropriate for nicotine dependence is unclear.

Unlike the DSM-IV, the FTQ was designed specifically to assess physical dependence on nicotine (Fagerström, 1978). Two of the eight original FTQ items, that assess (1) the time to first cigarette of the day after waking up and (2) the number of cigarettes smoked per day, were found to account for most of the variance of the FTQ (Lichtenstein \& Mermelstein, 1986). In addition, these items were found to be superior in predicting biochemical and behavioral indices of smoking (Heatherton et al. 1989, 1991; Kozlowski et al. 1994; Breslau \& Johnson, 2000; Prokhorov et al. 2000) and Heatherton and colleagues (1989) created a scale of just these two items, the Heaviness of Smoking Index (HSI). It has been suggested that time to first cigarette in the morning and number of cigarettes smoked per day may be the most useful and powerful indicators of nicotine dependence (Heatherton et al. 1989, 1991; Haddock et al. 1999). Individual differences in lifetime DSM-defined nicotine dependence, in number of cigarettes smoked per day, and in other tobacco use measures have been found to be under considerable genetic control. Heritability of DSM-III-R nicotine dependence was substantial in both a sample of Vietnam veteran male twins (60\%; True et al. 1999) and in a sample of Minnesota adolescents (44\%; McGue et al. 2000). In Virginia young adult female twins, Kendler and colleagues (1999) tested a causal common pathway model for lifetime regular smoking and nicotine dependence (based mostly on FTQ items) and found substantial heritability for regular smoking $(85 \%)$, substantial overlap in liability for regular smoking and nicotine dependence $(60 \%)$, and moderate residual genetic effects for nicotine dependence $(22 \%)$. Lifetime number of cigarettes smoked per day shows substantial heritability in adults (49-54\%; Kaprio et al. 1984; Carmelli et al. 1990; Swan et al. 1990; Hettema et al. 1999) and adolescents (84\%; Koopmans et al. 1999). Other tobacco use measures such as smoking initiation, lifetime regular smoking, and smoking persistence (current rather than ex-smoker at the time of assessment) are also strongly genetically influenced in adults (Heath et al. 1993, 1999; Heath \& Martin, 1993; True et al. 1997; Madden et al. 1999; Kendler et al. 2000) and in adolescents (Han et al. 1999; Koopmans et al. 1999; Maes et al. 1999). Family and adoption data also show that smoking initiation, persistence, and lifetime heavy smoking are correlated among biological siblings (Eaves \& Eysenck, 1980; Bierut et al. 1998; Osler et al. 2001).

The purpose of the present analysis was to examine the genetic and environmental influences on lifetime symptoms of nicotine dependence, assessed using DSM-IV criteria and HSI items, individually and jointly, to determine the genetic architecture of the clinical syndrome of nicotine dependence in a community sample of Australian adult female and male twins.

\section{METHOD}

\section{Sample}

Between 1980 and 1982, in response to media appeals and appeals through the Australian school system, twins born between 1964 and 1971 were registered with the Australian twin panel maintained by the Australian National Health and Medical Research Council. Twins either volunteered themselves or were volunteered by their parents. This twin cohort was first targeted for assessment in 1989-1992 ('1989 cohort') by mailed questionnaire survey (Gillespie et al. 2000; Heath et al. 2001). Between 1996 and 2000 , the 1989 cohort was interviewed by telephone using a structured diagnostic assessment for DSM-IV alcohol dependence, nicotine dependence, major depression, panic disorder, and childhood conduct disorder (APA, 1994) as well as non-diagnostic sections for social anxiety, suicidality, a screening for bipolar disorder, and a history of the consumption of alcohol, cigarettes and other forms of tobacco, and illicit drugs. The interview was a modified version of the diagnostic Semi-Structured Assessment for the Genetics of Alcoholism (Bucholz et al. 1994); the smoking section was modified from the Composite International Diagnostic Interview (Robins et al. 1988; Cottler et al. 1989). Telephone interview data were available from a total of 6257 individual twins (3454 women and 
2803 men). The overall individual response rate was $73.3 \%$, with a higher response rate for women than men $(77.7 \%$ v. $68.6 \%$; Heath et al. 2001). At the time of interview, all respondents ranged in age from 24 to 36 years old (mean age \pm s.D.: women $30 \cdot 0 \pm 2 \cdot 48$; men $29 \cdot 9 \pm 2 \cdot 45$ ).

This was a well educated sample, with $26 \cdot 3 \%$ of women and $25 \cdot 2 \%$ of men holding a university degree or higher, in addition to another $28.3 \%$ of women and $29 \cdot 3 \%$ of men holding a high-school diploma plus additional technical training. Australian census data show that $17 \cdot 5 \%$ of 25 - to 34-year-olds had bachelor's degrees in 1997, with this percentage rising to $20 \cdot 1 \%$ in 1999 and $24 \%$ in 2001; and that Australians with high-school diploma plus additional training comprised $31.4 \%$ in 1997 , $32.8 \%$ in 1999 , and $33.6 \%$ in 2001 (Australian Bureau of Statistics, 2001). Thus the 1989 twin sample was slightly better educated than their general population cohort. Forty-eight and a half per cent of the women and $87.4 \%$ of the men were employed full-time; for the women, an additional $22.7 \%$ were employed part-time (only $5.6 \%$ of the men) and $23.6 \%$ were homemakers $(0.4 \%$ of the men).

Analyses of smoking and nicotine dependence variables were performed on data available from a total of 6249 individual twins (3449 women and 2800 men) who answered either of the first two items of the smoking history interview section, which assessed whether respondents had ever experimented with cigarettes. Phenotypic analyses were restricted to twins who reported they had ever tried smoking or had experimented with cigarettes at least once (ever smokers; $n=3027$ women and 2553 men). The majority of the twins in this sample were ever smokers $(87.8 \%$ of the women and $91.2 \%$ of the men; $p<0.01)$. Data on cigarette smoking history were missing for five female and three male twins. Genetic analyses were conducted using twin pairs who were concordant ever smokers. Data on history of cigarette-smoking and nicotine dependence were available from both twins of 558 monozygotic (MZ) female, 419 MZ male, 424 dizygotic (DZ) female, 333 DZ male, and 559 DZ female-male twin pairs who were concordant ever smokers. We did not exclude from the analyses twins who had been exposed to nicotine, but never smoked regularly (i.e. experimenters). By including non-regular smokers in the genetic analysis, we sought to minimize the risk of obtaining biased estimates of the genetic contribution to the covariance structure of nicotine dependence symptoms, if some of the same genetic factors that contribute to risk of nicotine dependence symptoms also influence probability of becoming a regular smoker (Heath et al. 2002).

Zygosity was determined through standard questions about twin physical similarity and confusion by teachers and strangers. This method of zygosity determination shows $95 \%$ agreement with assignment based on blood tests (Eaves et al. 1989).

\section{Measures}

\section{Lifetime DSM-IV nicotine dependence criteria}

We used interview items that directly corresponded to the seven DSM-IV dependence criteria: tolerance to nicotine (assessed in response to an open-ended question about the largest number of cigarettes ever smoked in a single day: reporting 20 or more cigarettes was defined as tolerance); nicotine withdrawal symptoms; smoking more or over longer periods of time than intended; experiencing a persistent desire or unsuccessful attempts to cut down or quit smoking; spending a great deal of time smoking (operationalized as chain-smoking); reducing or giving up important activities because of an inability to smoke at such times; and continued smoking despite physical or psychological problems caused or exacerbated by smoking (APA, 1994).

\section{Lifetime DSM-IV nicotine dependence diagnosis} DSM-IV nicotine dependence was defined as experiencing three or more of the seven criteria within the same 12-month period.

\section{Lifetime Heaviness of Smoking Index items}

Time to first cigarette in the morning (TTF) and number of cigarettes smoked per day (CPD) were assessed for the respondents' heaviest period of smoking. TTF was a four-category measure: smoking less than $5 \mathrm{~min}, 6-30 \mathrm{~min}$, 31-60 min, or more than $60 \mathrm{~min}$, after waking up; CPD was a five-category measure: 1-5, 6-10, 11-15, 16-19, and 20+. 


\section{Lifetime Heaviness of Smoking Index-defined nicotine dependence}

TTF and CPD categories were coded as ordinal variables. Summing over TTF and CPD categories produced an eight-level scale ranging from light smokers at the lowest level who smoked maximum five CPD and had their first cigarette no earlier than one hour after waking up to smokers who smoked $20+$ CPD and had their first cigarette within $5 \mathrm{~min}$ of waking up. We collapsed this scale into four mutually exclusive categories of what we called nondependent, mildly dependent, moderately dependent, and dependent individuals (see note in Table 1 for details).

\section{Statistical analyses}

\section{Phenotypic data analysis}

Prevalence estimates of nicotine dependence symptoms and dependence definitions were computed for ever smokers; gender differences were evaluated using binomial and multinomial logistic regression in STATA (StataCorp, 2001), with the Huber-White robust estimator of variance (Huber, 1967; White, 1980, 1982) used to correct for non-independence of observations on twin pairs.

Exploratory factor analysis in ever smokers was performed using the structural equationmodeling program Mx (Neale et al. 2002). Polychoric correlations and asymptotic covariance matrices of the nine nicotine dependence items were estimated using PRELIS (Jöreskog \& Sörbom, 1995), separately for women and men. The computation of polychoric correlations for categorical variables assumes an underlying normally distributed latent liability for each measure, with thresholds superimposed to yield the discrete response categories. Factor loadings were estimated by asymptotic weighted least squares. Factor loadings generated in Mx were rotated using the SAS PROMAX option (SAS, 1999) to allow for a correlated factor structure. Internal consistency of resulting factor scales was evaluated using Cronbach's alpha.

\section{Genetic data analysis}

Genetic analyses were conducted using data from the total sample of twins who had ever smoked cigarettes, including experimenters. To the extent that there are overlapping genetic influences on progression from experimentation to regular smoking and on risk of nicotine dependence symptoms in those who became regular smokers, exclusion of twin pairs where one or both twins have never smoked regularly could lead to biased estimates of genetic and environmental parameters (Heath et al. 2002). Analyses were also repeated using all twin pairs, including twins who had never smoked even a single cigarette, but since the latter group was small, results were similar.

Univariate genetic analysis. Using data from twin pairs reared together, phenotypic variance can be decomposed into at least three sources: (1) additive effects of genes (A); (2) shared environmental effects common to members of a twin pair (C); and (3) environmental effects unique to each twin, including error variance (E). In place of $\mathrm{C}$, we can also test for nonadditive genetic effects (D) such as dominance (interaction between alleles of the same gene) or epistasis (gene-gene interaction). The reader is referred to a recent review by Boomsma and colleagues (2002) for details on twin methodology. The variance component designations A, $\mathrm{C}$ (or D) and $\mathrm{E}$ reflect the square of the regression coefficients of the variance component latent parameter on the measured variable $\left(a^{2}\right.$, $c^{2}, d^{2}$, and $e^{2}$ respectively). The ACE (or ADE) models were fit to the observed data (summary $\mathrm{MZ}$ and DZ twin pair covariance matrices for the quasi-continuous HSI measure; summary MZ and DZ twin pair contingency tables for all other measures) by the method of maximumlikelihood, with the goodness of fit of each model assessed by the $\chi^{2}$ test. Significance of the $\mathrm{A}$ or $\mathrm{C}$ (or D) variance component parameters was tested by fixing A, C (or D), or both parameters simultaneously to zero and comparing the fit of the reduced models to the full model using likelihood-ratio $\chi^{2}$ test. A significant likelihood-ratio $\chi^{2}$ test with degrees of freedom equal to the degrees of freedom difference between the full and reduced models indicates a significant deterioration of fit of the reduced, relative to the full, model, indicating that the parameter cannot be equated to zero. In order to test for gender differences in $\mathrm{A}, \mathrm{C}$ (or D), or $\mathrm{E}$ parameter estimates, we compared models in which estimates were free to vary across gender with 
reduced models in which estimates were equated across gender using the likelihood-ratio $\chi^{2}$ test. Genetic analyses were performed in Mx (Neale et al. 2002).

Multivariate genetic analysis. We tested two genetic mechanisms (cf. Kendler et al. 1987) via which covariance among nicotine dependence symptoms might arise. One mechanism, the independent (or general) pathway model, postulates that genetic and environmental factors act independently from one another in their influence on nicotine dependence symptom covariation. A second mechanism, the common pathway model, postulates that dependence symptom covariation can be explained by one or more intermediate latent phenotypes (e.g. some underlying mechanism, such as nicotine metabolism) that are themselves determined by genetic and environmental factors; thus, in the common pathway model, genetic and environmental factors contribute in a fixed ratio (correspondent to the heritability of the latent factor) to symptom covariation. Independent and common pathway models were fitted to summary MZ and DZ twin pair polychoric correlation matrices, using associated asymptotic covariance matrices as weight matrices, in $\mathrm{Mx}$, by the method of asymptotic weighted least squares. Because the common pathway model represents a series of constraints on the independent pathway model, the two can be formally compared using the $\chi^{2}$ difference test. Gender differences in parameter estimates were evaluated as in univariate analyses.

In the genetic factor model, failing to account for correlated measurement errors for different nicotine dependence items could result in biased estimates of genetic and environmental effects. In order to minimize the probability of misspecification of the genetic and shared environmental estimates, and to ensure that all error item variances and covariances were accounted for, we specified nine non-shared environmental factors (equal to the number of nicotine dependence items) loading in a triangular decomposition (Cholesky) pattern, where the first factor loaded on the first nicotine dependence item and on all subsequent items, the second factor loaded on the second dependence item and on all subsequent items, and so on. The general factor model applied to the additive genetic and shared
Table 1. Lifetime prevalence (\%) of DSM-IV and Heaviness of Smoking Index (HSI) nicotine dependence measures in female and male ever smokers (i.e. experimented with cigarettes at least once)

\begin{tabular}{|c|c|c|c|}
\hline $\begin{array}{l}\text { DSM-IV nicotine } \\
\text { dependence criteria }\end{array}$ & $\begin{array}{l}\text { Women } \\
(n=3027)\end{array}$ & $\begin{array}{c}\text { Men } \\
(n=2553)\end{array}$ & $\begin{array}{c}\text { OR } \\
(95 \% \mathrm{CI})\end{array}$ \\
\hline Tolerance & $37 \cdot 9$ & $48 \cdot 1$ & $1 \cdot 5(1 \cdot 4-1 \cdot 7)$ \\
\hline Withdrawal & $24 \cdot 1$ & $24 \cdot 6$ & N.S. \\
\hline Smoking more than intended & $42 \cdot 2$ & $40 \cdot 8$ & N.S. \\
\hline Difficulty quitting & $49 \cdot 4$ & $53 \cdot 0$ & $1 \cdot 2(1 \cdot 02-1 \cdot 3)$ \\
\hline Ever chain-smoked & $20 \cdot 9$ & $22 \cdot 1$ & N.S. \\
\hline Gave up activities to smoke & $6 \cdot 0$ & $5 \cdot 9$ & N.S. \\
\hline $\begin{array}{l}\text { Smoked despite physical or } \\
\text { emotional problems }\end{array}$ & $19 \cdot 4$ & $18 \cdot 3$ & N.S. \\
\hline Nicotine dependence diagnosis & $33 \cdot 0$ & $36 \cdot 0$ & $1 \cdot 1(1 \cdot 01-1 \cdot 3)$ \\
\hline \multicolumn{4}{|l|}{$\begin{array}{l}\text { HSI items and HSI-defined } \\
\text { nicotine dependence }\end{array}$} \\
\hline TTF $:<5$ min & $6 \cdot 7$ & $9 \cdot 6$ & $1 \cdot 6(1 \cdot 3-2 \cdot 0)$ \\
\hline $6-30 \mathrm{~min}$ & 11.9 & $15 \cdot 9$ & $1.5(1.3-1 \cdot 8)$ \\
\hline $31-60 \mathrm{~min}$ & $9 \cdot 8$ & $10 \cdot 8$ & $1 \cdot 2(1 \cdot 02-1 \cdot 5)$ \\
\hline $60+\min$ & $71 \cdot 5$ & $63 \cdot 7$ & $1 \cdot 0$ \\
\hline CPD : $20+$ & $18 \cdot 4$ & $27 \cdot 1$ & $1 \cdot 7(1 \cdot 4-1 \cdot 9)$ \\
\hline $16-19$ & $7 \cdot 6$ & $8 \cdot 8$ & $1 \cdot 3(1 \cdot 1-1 \cdot 6)$ \\
\hline $11-15$ & $10 \cdot 1$ & $9 \cdot 3$ & N.S. \\
\hline $6-10$ & $10 \cdot 5$ & $7 \cdot 7$ & N.s. \\
\hline $1-5$ & $53 \cdot 2$ & $47 \cdot 1$ & $1 \cdot 0$ \\
\hline \multicolumn{4}{|l|}{ HSI dependence } \\
\hline Dependent & $12 \cdot 2$ & $19 \cdot 1$ & $1 \cdot 8(1 \cdot 5-2 \cdot 1)$ \\
\hline Moderately dependent & $13 \cdot 8$ & $16 \cdot 5$ & $1 \cdot 4(1 \cdot 2-1 \cdot 6)$ \\
\hline Mildly dependent & $13 \cdot 2$ & $12 \cdot 3$ & N.S. \\
\hline Non-dependent & $60 \cdot 7$ & $52 \cdot 1$ & $1 \cdot 0$ \\
\hline
\end{tabular}

Odds ratios (OR) and 95\% confidence intervals (CI) indicate significant gender differences.

TTF and CPD categories were coded as ordinal variables by order of severity $(0-3$ for TTF, i.e. $60+\min$ to $<5 \mathrm{~min}$; and $0-4$ for $\mathrm{CPD}$, i.e. $1-5$ to $20+$ cigarettes per day), and summed across TTF and CPD categories to yield an HSI dependence score: non-dependent $(0-1)$, mildly dependent (2-3), moderately dependent (4-5), and dependent (6-7).

TTF, time to first cigarette in the morning; CPD, cigarettes per day.

environmental parameters is a submodel of a Cholesky decomposition model.

For both univariate and multivariate models, model parsimony (best fit with fewest parameters estimated) was assessed based on $\chi^{2}$ difference tests and the Aikake Information Criterion statistic (AIC; Akaike, 1987), calculated as model $\chi^{2}$ minus twice the degrees of freedom; lower AIC indicates better model fit.

\section{RESULTS}

\section{Prevalence}

Prevalence estimates of lifetime DSM-IV and HSI nicotine dependence items and nicotine 
Table 2. Phenotypic factor loadings of DSM$I V$ and HSI nicotine dependence items for female $(n=3027)$ and male $(n=2553)$ ever smokers, and inter-factor correlations $(r)$

\begin{tabular}{|c|c|c|c|c|}
\hline \multirow[b]{2}{*}{ Items } & \multicolumn{2}{|c|}{ Women } & \multicolumn{2}{|c|}{ Men } \\
\hline & \multicolumn{2}{|c|}{$(r=0 \cdot 75)$} & \multicolumn{2}{|c|}{$(r=0.74)$} \\
\hline (1) Tolerance & $0 \cdot 81$ & $0 \cdot 19$ & $0 \cdot 79$ & $0 \cdot 24$ \\
\hline (2) Withdrawal & $0 \cdot 29$ & 0.62 & $0 \cdot 16$ & 0.75 \\
\hline (3) More than intended & $0 \cdot 44$ & $0 \cdot 56$ & $0 \cdot 40$ & $0 \cdot 56$ \\
\hline (4) Difficulty quitting & $0 \cdot 35$ & $0 \cdot 72$ & $0 \cdot 31$ & $0 \cdot 78$ \\
\hline (5) Ever chain-smoked & $0 \cdot 32$ & $0 \cdot 47$ & $0 \cdot 36$ & $0 \cdot 43$ \\
\hline (6) Gave up activities & $0 \cdot 00$ & 0.68 & $0 \cdot 27$ & $0 \cdot 41$ \\
\hline (7) Smoke despite problems & $0 \cdot 25$ & $0 \cdot 58$ & $0 \cdot 10$ & $0 \cdot 74$ \\
\hline (8) TTF & $0 \cdot 77$ & $0 \cdot 11$ & $0 \cdot 75$ & $0 \cdot 16$ \\
\hline (9) CPD & $0 \cdot 95$ & $0 \cdot 08$ & $0 \cdot 91$ & $0 \cdot 14$ \\
\hline
\end{tabular}

TTF, time to first cigarette in the morning; CPD, cigarettes per day.

dependence definitions for female and male ever smokers are shown in Table 1. Significantly more men than women smokers reported tolerance $(48 \cdot 1 \% v .37 \cdot 9 \%)$, difficulty quitting smoking $(53.0 \% v .49 \cdot 4 \%)$, and met DSM-IV criteria for nicotine dependence $(36 \%$ v. $33 \%)$. Additionally, more men than women smoked within the first hour after waking $(36 \cdot 3 \%$ v. $28 \cdot 4 \%)$, more men than women were heavier smokers, averaging 16 or more cigarettes per day $(35.9 \%$ v. $26 \cdot 1 \%$, and, accordingly, more men than women were in the more severe HSI nicotine dependence categories.

\section{Factor analysis}

Phenotypic factor analysis performed on the seven DSM-IV nicotine dependence symptoms and the two HSI items in ever smokers identified a three-factor model as the best-fitting model in both women and men. However, only a single item, 'ever chain-smoked', had a substantial loading on the third factor in both genders. Therefore the two-factor solution was chosen as the most interpretable (Table 2). Although the pattern of item loadings across the two factors was similar across gender, with only the magnitude of loadings of some items ('gave up activities' and 'smoke despite problems') differing somewhat in women and men, the model constraining item loadings to be equal across gender was rejected $(p<0 \cdot 001)$. For both women and men, DSM-IV nicotine tolerance together with
TTF and CPD loaded highly on the first factor; four other DSM-IV dependence measures loaded more highly on the second factor - withdrawal, smoking more than intended, experiencing difficulty quitting, and smoking despite physical or psychological problems; DSM-IV ever chainsmoked loaded equally strongly on the two factors. Thus for both genders, the two-factor solution seemed to distinguish a tolerance/ quantity smoked factor (on which time to first cigarette also had a strong loading), and a second factor associated with withdrawal and difficulty quitting smoking. However, the two factors were highly correlated $(r=0.75$ in women, $r=0.74$ in men). Restricting analysis to regular smokers $(100+$ cigarettes lifetime; results not shown) showed that item loadings could be constrained across gender and the pattern and magnitude of factor loadings across the two latent factors were nearly identical to those shown for the men in Table 2. Thus, factor analysis results suggest a similar pattern of endorsement of nicotine dependence symptoms between women and men, particularly among lifetime regular smokers.

\section{Internal consistency}

Internal consistency was acceptable for both factor scales for both female and male ever smokers. For the tolerance/quantity smoked factor, Cronbach's alpha was 0.78 for the women and 0.79 for the men. For the withdrawal/difficulty quitting factor, alpha estimates were 0.78 for the women and 0.78 for the men; 'gave up activities' had the lowest correlation with total scale score for both women $(0 \cdot 30)$ and men $(0 \cdot 27)$ compared to the remaining dependence items loading on this factor (range $0.50-0.75)$ and internal consistency improved to 0.81 and 0.80 for women and men, respectively, when this item was excluded.

\section{Univariate genetic analysis}

In the sample of twin pairs concordant for ever smoking, Table 3 shows that for all dependence symptoms, except for 'difficulty quitting', A, C, and $\mathrm{E}$ effects could be equated across gender; additionally, shared environmental effects did not contribute significantly to phenotypic variance, although their point estimates and associated $95 \%$ confidence intervals are shown in 
Table 3. Univariate estimates (\%) of additive genetic $(A)$, shared environmental $(C)$, and non-shared environmental $(E)$ influences and associated $95 \%$ CI for DSM-IV and HSI nicotine dependence items and definitions in twin pairs concordant for ever smoking

\begin{tabular}{|c|c|c|c|c|c|c|c|}
\hline \multirow[b]{2}{*}{ Items } & \multicolumn{3}{|c|}{ Variance component estimates } & \multicolumn{4}{|c|}{ Model fit statistics } \\
\hline & A $(95 \% \mathrm{CI})$ & $\mathrm{C}(95 \% \mathrm{CI})$ & $\mathrm{E}(95 \% \mathrm{CI})$ & $\chi^{2}$ & df & $p$ & AIC \\
\hline (1) Tolerance & $73(54-79)$ & $1(0-17)$ & $26(21-32)$ & $16 \cdot 2$ & 7 & $0 \cdot 02$ & $2 \cdot 2$ \\
\hline (2) Withdrawal & $53(37-61)$ & $0(0-12)$ & $47(39-55)$ & $3 \cdot 8$ & 7 & $0 \cdot 80$ & $-10 \cdot 1$ \\
\hline (3) More than intended & $62(43-69)$ & $0(0-16)$ & $37(31-45)$ & 11.9 & 7 & $0 \cdot 11$ & $-2 \cdot 1$ \\
\hline \multicolumn{8}{|l|}{ (4) Difficulty quitting } \\
\hline Women & $68(60-75)$ & $0(0-60)$ & $32(25-40)$ & $12 \cdot 9$ & 5 & $0 \cdot 02$ & $2 \cdot 9$ \\
\hline Men & $54(28-89)$ & $26(0-49)$ & $20(14-28)$ & & & & \\
\hline (5) Ever chain-smoked & $45(23-54)$ & $0(0-16)$ & $55(46-65)$ & $9 \cdot 4$ & 7 & $0 \cdot 22$ & $-4 \cdot 6$ \\
\hline (6) Gave up activities & $26(0-45)$ & $0(0-27)$ & $74(55-93)$ & $7 \cdot 7$ & 7 & $0 \cdot 36$ & $-6 \cdot 3$ \\
\hline (7) Smoke despite problems & $39(7-51)$ & $2(0-25)$ & $59(49-72)$ & $10 \cdot 0$ & 7 & $0 \cdot 19$ & $-4 \cdot 0$ \\
\hline (8) TTF & $68(51-73)$ & $0(0-13)$ & $32(27-38)$ & $83 \cdot 7$ & 58 & $0 \cdot 02$ & $-32 \cdot 3$ \\
\hline (9) CPD & $70(56-75)$ & $0(0-12)$ & $30(25-34)$ & $147 \cdot 7$ & 94 & $<0 \cdot 001$ & $-40 \cdot 3$ \\
\hline \multicolumn{8}{|l|}{ Nicotine dependence } \\
\hline DSM-IV & $56(40-63)$ & $0(0-13)$ & $44(36-51)$ & $9 \cdot 8$ & 7 & $0 \cdot 21$ & $-4 \cdot 3$ \\
\hline HSI & $71(59-75)$ & $0(0-10)$ & $29(25-34)$ & $109 \cdot 4$ & 58 & $<0.001$ & $-6 \cdot 6$ \\
\hline
\end{tabular}

Table 3. All individual symptoms were significantly heritable $(45-73 \%$; except for 'gave up activities') as were DSM-IV (56\%) and HSI $(71 \%)$ definitions of nicotine dependence. For 'gave up activities', it was not possible to distinguish between additive genetic versus shared environmental influences because there was no significant deterioration of model fit when either $\mathrm{A}$ or $\mathrm{C}$ were individually dropped from the model; however, dropping both simultaneously significantly reduced model fit, suggesting significant familial influences.

There was no evidence for a significant contribution of non-additive genetic effects to phenotypic variance for any item.

\section{Multivariate genetic analysis}

In a four-group analysis of data from pairs who were concordant ever smokers, excluding unlike-sex twin pairs, the best-fitting model estimated a single genetic and a single shared environmental common factor (AIC $=779 \cdot 46$; likelihood-ratio test versus full Cholesky model: $\left.\chi^{2}=56 \cdot 20, \mathrm{df}=108, p=0 \cdot 99\right)$. Adding a second genetic common factor $(\mathrm{AIC}=791.42)$ or a second shared environmental common factor $(\mathrm{AIC}=787.55)$ worsened the fit of the model by AIC, and did not produce a significant improvement in fit by likelihood-ratio $\chi^{2}$ test $\left(\chi^{2}=24 \cdot 04, \mathrm{df}=18, p=0 \cdot 15 ; \chi^{2}=27 \cdot 91, \mathrm{df}=18\right.$, $p=0 \cdot 06)$. A model which constrained genetic and environmental factor loadings to be the same in females and males $(\mathrm{AIC}=1176)$ and a common pathway model $(\mathrm{AIC}=1090)$ both gave substantially worse fits. Genetic common factor loadings under the best-fitting model were substantial (data not shown), and somewhat higher in males $(0.67-0.89)$ than in females (0.61-0.81), with the lowest loadings observed for 'ever chain-smoked' and 'gave up activities' in both genders $(0.53$ and 0.74 for females, 0.67 and 0.71 for males, respectively); and, in females, for 'smoke despite problems' $(0 \cdot 61)$ and 'withdrawal' $(0 \cdot 68)$, with all other loadings being 0.75 or higher. Non-zero genetic specific variances were obtained for only three items, and in females only (TTF: $0 \cdot 27$; withdrawal: 0.26; 'ever chain-smoked': 0-21). Shared environmental common factor loadings were generally higher in females (zero for 'gave up activities', $0 \cdot 18-0.42$ for other items) than in males (zero for 'more than intended', $0 \cdot 10-0 \cdot 35$ for other items), but were substantially lower than the corresponding genetic common factor loadings. A single non-zero shared environmental specific variance was obtained in each gender (female: $0 \cdot 12$ for 'more than intended'; males: 0.20 for 'withdrawal').

The five-group analysis of pairs who were concordant ever smokers uncovered important genotype $\times$ gender interaction effects. The fit of a model estimating a single genetic and a single shared environmental common factor for each gender $\left(\chi^{2}=2268 \cdot 59, \mathrm{df}=621, \mathrm{AIC}=1026\right)$ was 
improved on either by allowing the correlation between shared environmental effects, $\mathrm{rC}$, in unlike-sex pairs, to deviate from unity $(\mathrm{AIC}=$ 1017) or by allowing the correlation between genetic effects in unlike-sex pairs, $\mathrm{rG}$, to take values less than $0.5(\mathrm{AIC}=1010)$. Compared to the one genetic and one shared environmental factor model with $\mathrm{rC}=1$ and $\mathrm{rG}=0 \cdot 5$, estimating a second genetic common factor $(\mathrm{AIC}=995)$ or a second shared environmental common factor $(\mathrm{AIC}=1009)$ yielded an improvement in fit, with the two genetic factor model giving the better fit by AIC. A model that estimated two genetic and two shared environmental common factors $(\mathrm{AIC}=1002)$ gave a substantial improvement in fit over the model with two shared environmental and a single genetic common factor $\left(\chi^{2}=43 \cdot 25, \mathrm{df}=18, p<0 \cdot 001\right)$ but only a marginal improvement in fit over the two genetic/one shared environment common factor model $\left(\chi^{2}=29 \cdot 30, \mathrm{df}=18, p=0 \cdot 045\right)$, and a worsening of fit compared to the latter by AIC. Adding a third genetic factor did not give any further improvement over the latter model $\left(\mathrm{AIC}=1016 ; \chi^{2}=15 \cdot 40, \mathrm{df}=18, p=0.63\right)$. Thus the two genetic/one shared environmental common factor model was identified as the bestfitting model in the five-group analyses. Allowing correlations between the first or second genetic factors in unlike-sex pairs to take values less than 0.5 gave no change in fit. However, genetic factor loadings on the second genetic factor under the best-fitting model were opposite in sign in males versus females (equivalent to a negative correlation between genetic effects associated with the second factor in males versus females). Likewise, shared environmental common factor loadings were opposite in sign. Genetic and shared environmental specific factor loadings were similar to those observed in the four-group analysis.

Unrotated common factor loadings, under the best-fitting five-group model, are summarized in Table 4. The first genetic factor in each gender had high loadings on all items, with a pattern of loadings very similar to that seen for the single genetic factor estimated in the fourgroup solution. In females, the second genetic factor had high loadings only on items 'gave up activities' and 'difficulty quitting'; whereas in males the second genetic factor had moderate loadings on items broadly related to amount
Table 4. Factor loadings of DSM-IV and HSI nicotine dependence items on two orthogonal additive genetic factors ( $A F 1$ and $A F 2)$ and one shared environmental factor $(C)$, for women and men ever smokers

\begin{tabular}{|c|c|c|c|c|c|c|}
\hline \multirow[b]{2}{*}{ Items } & \multicolumn{3}{|c|}{ Women } & \multicolumn{3}{|c|}{ Men } \\
\hline & AF1 & AF2 & $\mathrm{C}$ & AF1 & AF2 & $\mathrm{C}$ \\
\hline (1) Tolerance & $0 \cdot 88$ & -0.09 & $0 \cdot 03$ & $0 \cdot 77$ & $0 \cdot 22$ & $0 \cdot 26$ \\
\hline (2) Withdrawal & 0.67 & $-0 \cdot 15$ & $-0 \cdot 15$ & $0 \cdot 78$ & $0 \cdot 12$ & $0 \cdot 22$ \\
\hline (3) More than intended & $0 \cdot 83$ & -0.08 & $-0 \cdot 16$ & $0 \cdot 80$ & $0 \cdot 18$ & $0 \cdot 28$ \\
\hline (4) Difficulty quitting & $0 \cdot 76$ & $-0 \cdot 31$ & -0.08 & $0 \cdot 78$ & $0 \cdot 10$ & $0 \cdot 27$ \\
\hline (5) Ever chain-smoked & $0 \cdot 70$ & $0 \cdot 05$ & -0.06 & $0 \cdot 57$ & $0 \cdot 09$ & $0 \cdot 12$ \\
\hline (6) Gave up activities & 0.57 & -0.49 & -0.05 & 0.64 & $0 \cdot 23$ & $0 \cdot 27$ \\
\hline $\begin{array}{l}\text { (7) Smoke despite } \\
\text { problems }\end{array}$ & $0 \cdot 71$ & $0 \cdot 00$ & $-0 \cdot 17$ & $0 \cdot 79$ & $0 \cdot 00$ & $0 \cdot 46$ \\
\hline (8) $\mathrm{TTF}$ & 0.78 & $0 \cdot 03$ & $-0 \cdot 12$ & $0 \cdot 81$ & $0 \cdot 32$ & $0 \cdot 32$ \\
\hline (9) CPD & $0 \cdot 86$ & -0.08 & -0.04 & $0 \cdot 80$ & $0 \cdot 22$ & $0 \cdot 26$ \\
\hline
\end{tabular}

TTF, time to first cigarette in the morning; CPD, cigarettes per day.

smoked (TTF, CPD, tolerance) as well as 'gave up activities' and 'more than intended'.

Item non-shared environmental variances and correlations under the best-fitting model are summarized in Table 5. Inter-item correlations are much higher in males than in females, with many estimated correlations in males 0.9 or higher in magnitude. This suggests that in males, non-shared environmental influences are largely associated with differences in the extent of progression of cigarette smoking, whereas in females non-shared environmental contributions to symptom profile are observed.

\section{DISCUSSION}

The DSM-IV criteria that are used to diagnose substance dependence have been applied to nicotine, as well as to alcohol and illicit drugs (APA, 1994). The Heavy Smoking Index items time to first cigarette in the morning and number of cigarettes smoked per day (Heatherton et al. 1989) comprise two of the original eight items of the Fagerström Tolerance Questionnaire (Fagerström, 1978), which was designed to assess physical dependence to nicotine. The goal of this paper was to conduct multivariate genetic analysis of DSM-IV and HSI items to define heritable aspects of nicotine dependence, thereby adding to the body of knowledge on the construct validity and properties of 
Table 5. Proportion of variance (\%) attributable to non-shared environmental factors for each nicotine dependence item (shown across the diagonal in bold), and pair-wise non-shared environmental correlations among nicotine dependence items (shown in the off diagonal) for women (top) and men (bottom) ever smokers

\begin{tabular}{|c|c|c|c|c|c|c|c|c|c|}
\hline & Tolerance & Withdrawal & Intend & Quit & Chain & Activity & Problems & TTF & CPD \\
\hline \multicolumn{10}{|l|}{ Women } \\
\hline Tolerance & $21 \cdot 6$ & & & & & & & & \\
\hline Withdrawal & 0.84 & $42 \cdot 3$ & & & & & & & \\
\hline Intend & 0.79 & 0.89 & $27 \cdot 5$ & & & & & & \\
\hline Quit & $0 \cdot 90$ & 0.89 & $0 \cdot 92$ & $32 \cdot 3$ & & & & & \\
\hline Chain & $0 \cdot 70$ & $0 \cdot 50$ & 0.67 & 0.66 & 46.9 & & & & \\
\hline Activity & $0 \cdot 83$ & $0 \cdot 83$ & 0.91 & 0.99 & $0 \cdot 61$ & $26 \cdot 8$ & & & \\
\hline Problems & 0.60 & 0.57 & 0.52 & 0.62 & $0 \cdot 28$ & $0 \cdot 60$ & $48 \cdot 3$ & & \\
\hline TTF & $0 \cdot 72$ & $0 \cdot 65$ & 0.47 & 0.74 & $0 \cdot 29$ & $0 \cdot 71$ & $0 \cdot 33$ & $31 \cdot 1$ & \\
\hline CPD & $0 \cdot 91$ & $0 \cdot 72$ & $0 \cdot 65$ & 0.79 & $0 \cdot 44$ & $0 \cdot 82$ & $0 \cdot 45$ & $0 \cdot 74$ & $25 \cdot 1$ \\
\hline \multicolumn{10}{|l|}{ Men } \\
\hline Tolerance & $27 \cdot 3$ & & & & & & & & \\
\hline Withdrawal & 0.85 & $23 \cdot 7$ & & & & & & & \\
\hline Intend & $0 \cdot 90$ & 0.85 & $29 \cdot 3$ & & & & & & \\
\hline Quit & $0 \cdot 96$ & 0.93 & $0 \cdot 96$ & $30 \cdot 9$ & & & & & \\
\hline Chain & $0 \cdot 82$ & 0.67 & 0.94 & $0 \cdot 82$ & $44 \cdot 8$ & & & & \\
\hline Activity & 0.98 & 0.91 & 0.94 & 0.99 & 0.82 & $44 \cdot 5$ & & & \\
\hline Problems & $0 \cdot 90$ & 0.93 & 0.92 & 0.98 & $0 \cdot 74$ & $0 \cdot 96$ & $31 \cdot 3$ & & \\
\hline TTF & $0 \cdot 84$ & 0.79 & 0.61 & $0 \cdot 81$ & $0 \cdot 42$ & $0 \cdot 83$ & 0.79 & $17 \cdot 7$ & \\
\hline CPD & 0.96 & 0.73 & 0.78 & 0.86 & 0.75 & 0.89 & 0.75 & 0.81 & $26 \cdot 4$ \\
\hline
\end{tabular}

Intend, more than intended; Quit, difficulty quitting; Chain, ever chain-smoked; Activity, gave up activity; Problems, smoking despite problems; TTF, time to first cigarette; CPD, cigarettes per day.

the nosology currently used to define nicotine dependence.

Phenotypic factor analysis showed clustering of symptoms of tolerance to nicotine together with the two heavy smoking index items on one factor for women and men, which is not surprising considering that both tolerance and number of cigarettes smoked per day were operationalized in terms of quantity of cigarettes smoked (albeit different items), and that time to first cigarette upon waking and cigarettes smoked per day have been shown to be highly correlated in other general population studies (Etter et al. 1999; Haddock et al. 1999; Radzius et al. 2001). The weak loading of the time to first cigarette item on the second factor, on which nicotine withdrawal had a strong loading, suggests that contrary to what has previously been suggested (APA, 1994), time to first cigarette may not be a useful measure of nicotine withdrawal. Alternatively, our retrospective measure of withdrawal may not adequately capture symptoms of withdrawal following overnight abstinence.

In the second factor 'gave up activities' was the only item that loaded significantly in women but not in men. However, 'gave up activities' had the lowest correlation with total factor scale score, and when this measure was excluded, factor scale internal consistency improved in women and men. In another study, 'gave up activities' did not load on either of two factors identified in a factor analysis of DSM-III-R nicotine dependence symptoms in young adult female and male lifetime smokers (current and ex-smokers) similar in age and year of assessment, as reported in this study (21-30 years old; interviewed at home in 1989; Johnson et al. 1996), and the authors excluded this item from subsequent creation of factor scales. Additionally, in our analyses, 'gave up activities' was the least commonly endorsed nicotine dependence item by women and men, and was found in genetic analyses of these data to be mainly influenced by non-shared environmental factors. Taken together, these results suggest that the DSM-IV substance dependence criterion of 'important social, occupational, or recreational activities are given up because of substance use', as measured in our assessment, may not be a salient indicator of nicotine dependence in adults. Additionally, the importance of this criterion will likely vary in response to social and cultural changes in regulation of smoking practices. 
'Ever chain-smoked' did not preferentially load on one phenotypic factor or the other, but showed significant and high loadings on a third factor for women $(0.97)$ and men $(0.83)$, indicating that 'ever chain-smoked' is not endorsed in a pattern that correlates with endorsement of the remaining nicotine dependence symptoms. It may be that 'ever chain-smoked' is too broad a measure or that it may occur only intermittently for many smokers, such as at times of stress, rather than represent a consistent, specific pattern of smoking behavior. Additionally, this item, which corresponds to the DSM-IV dependence criterion 'a great deal of time spent in using the substance', assessed at a general population level, may be more relevant to illicit substance use. The DSM-IV distinguishes between physiological dependence associated with tolerance or withdrawal and non-physiological (psychological) dependence associated with the lack of tolerance and withdrawal (APA, 1994). Since tolerance and withdrawal each loaded on separate factors, it appears that phenotypic factor analysis captured two aspects of physiological dependence to nicotine, and psychological symptoms of nicotine dependence loaded on the same factor as withdrawal. The clustering of these nicotine dependence items has been termed 'failed cessation' by others (Johnson et al. 1996).

There was evidence for substantial genetic influences accounting for individual differences in nicotine dependence measures (range 45-73\% ; except for 'gave up activities' where there was only evidence for weak familial effects). Our genetic estimate for DSM-IV nicotine dependence $(56 \%)$ is similar to that for DSM-III-R nicotine dependences assessed in Vietnam veteran male twins $(60 \%$; True et al. 1999); the heritability estimate for daily cigarette consumption was high $(70 \%)$ when the analysis included twin pairs concordant for ever smoking, relative to other estimates $(50 \%$; Hettema et al. 1999). Heritability was more modest, however, when analysis was restricted to regular smokers ( $51 \%$; data not shown) and agreed with heritability estimates (about 50\%) reported previously in adult current and exsmoker lifetime regular smokers (Kaprio et al. 1984; Carmelli et al. 1990; Swan et al. 1990, 1996, 1997). Exclusion of twin pairs, where one or both twins has never smoked, or never smoked regularly, will lead to a biased estimate of the importance of genetic influences if in fact some of the same genetic factors that influence risk of nicotine dependence also influence risk of experimentation with cigarettes, or risk of becoming a regular smoker. In many cases, for traits where shared environmental influences are modest or negligible, it will lead to an underestimate of the importance of genetic influences. Exclusion of groups of types of smokers would be valid only in the case where liability for smoking experimentation or occasional smoking is uncorrelated with liability for regular smoking or nicotine dependence (Prescott \& Kendler, 1995). In fact, two-stage modeling of dimensions of smoking initiation and smoking persistence (Heath, 1990; Heath \& Martin, 1993; Heath et al. 1998; Madden et al. 1999) and of smoking initiation and number of cigarettes smoked per day in adolescents and young adults (Koopmans et al. 1999) have shown evidence of shared genetic risk. Heritability estimates derived under a two-stage model (Heath et al. 2002) that estimates jointly genetic effects on risk of becoming a regular smoker, and correlated genetic effects on individual symptoms of nicotine dependence in those who have become regular smokers, should yield a less biased estimate of heritability, but this is beyond the scope of the current paper.

The univariate genetic models did not fit the data for time to first cigarette in the morning and number of cigarettes smoked per day, or for their joint definition of nicotine dependence, suggesting that different genetic and environmental influences may determine risk of lower levels of smoking or smoking right after waking in the morning versus higher levels of smoking or smoking later in the day.

In the multivariate genetic models, although the results of four-group and five-group analyses appeared somewhat different, with the best-fitting model in the four-group analysis including a single genetic factor but that for the five-group analysis including two genetic factors in women and men, there was a trend for the addition of a second genetic factor to improve goodness-of-fit in the four-group analysis by likelihood-ratio $\chi^{2}$ test criterion $(p=0 \cdot 045)$. In both four- and five-group analyses, results were consistent with the existence of a general genetic factor with high loadings of all items, albeit with 
somewhat reduced loadings for items 'gave up activities' in both genders, and for 'withdrawal' in women and 'ever chain-smoked' in men. The second genetic factors had loadings that were opposite in sign in males and females, implying a negative genetic correlation, and were characterized by somewhat different items (' gave up activities' and 'difficulty quitting' in women; items related to amount smoked in men). Until this pattern has been replicated, these loadings should be interpreted with caution: once the first genetic common factor is controlled for, power for resolving the residual genetic structure would be expected to be somewhat low. However, the fact that a similar structure for the second genetic factor was observed in fourgroup (data not shown) as well as five-group analyses indicates that it is not simply an idiosyncratic pattern of cross-twin pair correlations in unlike-sex pairs that is leading to the observed pattern of genetic factor loadings.

The present analyses add to growing evidence for substantial genetic influence on nicotine dependence (Sullivan \& Kendler, 1999; True et al. 1999). DSM-IV substance dependence criteria, which were developed to be applicable to a range of substances (Cottler et al. 1995), also appear to be useful indicators of nicotine dependence. Five nicotine dependence symptoms, in particular, had high phenotypic and genetic factor loadings as well as high heritability: tolerance, time to first cigarette in the morning, number of cigarettes smoked per day, withdrawal, and difficulty quitting. What makes some of these items particularly attractive is that they can be investigated in animal models. Animal studies show that development of tolerance to nicotine and quantity of self-administered nicotine are under significant genetic influences (Marks et al. 1991; Robinson et al. 1996) and are associated with changes in nicotine binding in the brain (Collins \& Marks, 1989, 1991; Pietilä et al. 1998). Nicotine withdrawal can be considered an index of nicotine dependence in rodents and has been shown to be mediated by central nicotinic receptors and a number of neurotransmitter systems (Kenny \& Markou, 2001).

Several limitations of this study should be considered. This is a large-scale community study, but conclusions drawn may be specific to the age range studied (24-36), to the time of assessment (1996-2000), and to the country of
Australia. Genetic or environmental factors affecting aspects of cigarette use and dependence may change with advancing age or may be different during adolescence (or may be associated with length of time smoked), across birth cohorts, or across societies. For example, it has been shown that an overlap in genetic and environmental risk factors for starting to smoke and for continuing to smoke decreases with age when comparing age cohorts of 18-25-year-old and 36-46-year-old female and male twins (Madden et al. 1999). Evidence for greater importance of shared environmental effects on starting to smoke in Scandinavian relative to Australian men (Madden et al. 1999) further suggests cultural differences in cigarettesmoking.

Our data are based on retrospective selfreport and are thereby liable to recall bias, particularly for respondents who are not current smokers. However, lifetime symptoms and diagnoses of nicotine and other substance use have been shown to have acceptable reliability (Cottler et al. 1989; Langenbucher et al. 1994) and self-reports of smoking have been found to be accurate when validated through biochemical measures (Patrick et al. 1994).

Inclusion of never smokers in the multivariate genetic modeling represents a confound of the genetic and environmental influences on smoking initiation and on risk of nicotine dependence in those who have become smokers and may introduce bias in parameter estimates. In the univariate approach, there are data-analytic strategies that can be applied under certain strong but testable assumptions to more rigorously separate genetic influences associated with initiation of regular smoking and genetic influences associated with risk of dependence in those who have become regular smokers (e.g. Heath et al. 2002), avoiding some of the somewhat arbitrary assumptions that have been used in the past to achieve model identification (e.g. Heath \& Martin, 1993). While generalization of such an approach to the estimation of multivariate models is achievable in theory, this rapidly becomes numerically intractable in the multivariate case unless the number of variables being analyzed is small (four or fewer), and thus could not be applied in the present analysis. Since we consider it plausible that there are important genetic influences that are common to 
both progression from experimentation to regular smoking and risk of dependence in those who become regular smokers (for example, conduct disorder: cf. Madden et al. 1997), we have preferred to include experimenters as well as smokers in our multivariate genetic analyses, to avoid the potential underestimation of the importance of genetic influence that would arise by excluding such individuals. Results when never smokers as well as experimenters were included in our analyses were similar (not shown), but numbers of never smokers were relatively small.

The twin method relies on the assumption that trait-relevant environmental influences contribute equally to the resemblance of $\mathrm{MZ}$ and DZ twin pairs. Environmental influences that are more similar for MZ compared to DZ twin pairs may be associated with a trait of interest and could account for greater similarity between MZ than DZ twins (i.e. inappropriately inflating estimates of trait heritability). Such characteristics, for example, physical twin similarity (Hettema et al. 1995), self-perceived zygosity (Xian et al. 2000), perceived zygosity and associated parental approach to rearing their twins (Kendler et al. 1993, 1994; Kendler \& Gardner, 1998; Cronk et al. 2002), and physical and emotional closeness between the twins (LaBuda et al. 1997; Kendler \& Gardner, 1998; Cronk et al. 2002) have been shown to be uncorrelated with zygosity differences in a number of psychiatric disorders such as alcohol and illicit drug dependence, major depression, anxiety, and externalizing disorders, supporting the validity of the equal environmental assumption in twin studies assessing these disorders. The equal environment assumption has also been found to be valid for DSM-III-R nicotine dependence in female (Kendler \& Gardner, 1998) and male twins (Xian et al. 2000). However, greater sharing of peer group in adolescence in $\mathrm{MZ}$ compared to DZ twins is associated with greater MZ compared to DZ twin similarity for smoking initiation (Kendler \& Gardner, 1998), which may not be surprising considering that peer smoking is a strong and important predictor of adolescent smoking initiation (Chassin et al. 2000; Mayhew et al. 2000; Kobus, 2003), and that MZ twins are more likely to share peers compared to DZ twins. Our sample of twins included young adults who were past adolescence, when the majority of adult smokers initiate smoking (Upadhyaya et al. 2002), and considering that nicotine dependence can be observed shortly after the start of regular smoking (DiFranza et al. 2002), the possible violation of the equal environment assumption with respect to smoking initiation would not be relevant to our analyses. We tested, therefore, the equal environment assumption with respect to DSM-IV and HSI definitions of nicotine dependence. We separated the sample into two groups, those who reported always sharing the same friends in childhood and early adolescence and those who reported sharing the same friends less often. We found no group differences in estimates of the relative contribution of genetic and shared environmental influences on DSM-IV and HSI definitions of dependence, suggesting that the equal environment assumption is valid for these measures of nicotine dependence in our data.

In conclusion, we found that nearly all symptoms of nicotine dependence were moderately to highly heritable and that nicotine dependence symptom covariance was influenced by two genetic and one shared environmental factors in both women and men, with symptoms on the second genetic factors loading opposite in sign in women versus men, suggesting a negative genetic correlation and implying that different genetic factors may, in part, operate in women compared to men. Our analyses suggest that the two DSM-IV criteria of giving up or reducing important activities in order to smoke and spending a lot of time using nicotine (i.e. chainsmoking) may contribute little to our measurement of nicotine dependence for the purpose of genetic research; while the DSM-IV criteria tolerance, withdrawal, and experiencing difficulty quitting, along with the two HSI index items may best signify nicotine dependence, and, considering their substantial heritability, they may also be fruitful phenotypes for genemapping efforts.

\section{ACKNOWLEDGMENTS}

The authors acknowledge the statistical help of Bill Howells and Dr Julie Grant and thank Dr Qiang Fu, Dr Anne Glowinski, Dr Michele Pergadia, and Dr Michael Lynskey for helpful comments on earlier versions of this manuscript. 
We also thank the interviewers, project coordinators, and the twins who made this work possible. This work was funded through AA11998 and AA07728 (A.C.H.), DA12854, DA00272, and DA12540 (P.A.F.M.), and DA07261 (C.N.L.).

\section{REFERENCES}

Akaike, H. (1987). Factor analysis and AIC. Psychometrika 52, 317-332.

APA (1994). Diagnostic and Statistical Manual of Mental Disorders (4th edn). American Psychiatric Association: Washington, DC.

Australian Bureau of Statistics (2001). Education and work, Australia (cat. no. 6227.0).

Bierut, L. J., Dinwiddie, S. H., Begleiter, H., Crowe, R. R., Hesselbrock, V., Nurnberger, J. I., Porjesz, B., Schuckit, M. \& Reich, T. (1998). Familial transmission of substance dependence, alcohol, marijuana, cocaine, and habitual smoking. A report from the Collaborative Study on the Genetics of Alcoholism. Archives of General Psychiatry 55, 982-988.

Boomsma, D., Busjahn, A. \& Peltonen, L. (2002). Classical twin studies and beyond. Nature Review Genetics 3, 872-882.

Breslau, N. \& Johnson, E. O. (2000). Predicting smoking cessation and major depression in nicotine-dependent smokers. American Journal of Public Health 90, 1122-1127.

Bucholz, K. K., Cadoret, R., Cloninger, C. R., Dinwiddie, S. H., Hesselbrock, V. M., Nurnberger Jr., J. I., Reich, T., Schmidt, I. \& Schuckit, M. A. (1994). A new, semi-structured psychiatric interview for use in genetic linkage studies: a report on the reliability of the SSAGA. Journal of Studies on Alcohol 55, 149-158.

Carmelli, D., Swan, G. E., Robinette, D. \& Fabsitz, R. R. (1990). Heritability of substance use in the NAS-NRC twin registry. Acta Geneticae Medicae et Gemellologiae 39, 91-98.

Centers for Disease Control (CDC) (2002). Annual smoking: attributable mortality, years of potential life lost and economic costs - United States 1995-1999. Morbidity and Mortality Weekly Report 51, 300-303.

Chassin, L., Presson, C. C., Pitts, S. C. \& Sherman, S. J. (2000). The natural history of cigarette smoking from adolescents to adulthood in a Midwestern community sample: multiple trajectories and their psychosocial correlates. Health Psychology 19 , 223-231.

Collins, A. C. \& Marks, M. J. (1989). Chronic nicotine exposure and brain nicotinic receptors - influence of genetic factors. Progress in Brain Research 79, 137-146.

Collins, A. C. \& Marks, M. J. (1991). Progress towards the development of animal models of smoking-related behaviors. Journal of Addictive Diseases 10, 109-126.

Cottler, L. B., Robins, L. N. \& Helzer, J. E. (1989). The reliability of the CIDI-SAM: a comprehensive substance abuse interview. British Journal of Addiction 84, 801-814.

Cottler, L. B., Schuckit, M. A., Helzer, J. E., Crowley, T., Woody, G., Nathan, P. \& Hughes, J. (1995). The DSM-IV field trial for substance use disorders: major results. Drug and Alcohol Dependence 38, 59-69.

Cronk, N. J., Slutske, W. S., Madden, P. A. F., Bucholz, K. K., Reich, W. \& Heath, A. C. (2002). Emotional and behavioral problems among female twins: an evaluation of the equal environments assumption. Journal of the American Academy of Child and Adolescent Psychiatry 41, 829-837.

Dani, J. A., Ji, D. \& Zhou, F.-M. (2001). Synaptic plasticity and nicotine addiction. Neuron 31, 349-352.

DiFranza, J. R., Savageau, J. A., Rigotti, N. A., Fletcher, K., Ockene, J. K., McNeill, A. D., Coleman, M. \& Wood, C. (2002). Development of symptoms of tobacco dependence in youths: 30 -month follow-up data from the DANDY study. Tobacco Control 11, 228-235.
Eaves, L. J. \& Eysenck, H. J. (1980). The genetics of smoking. In The Causes and Effects of Smoking (ed. H. J. Eysenck), pp. 140-314. Maurice Temple Smith: London.

Eaves, L. J., Eysenck, H. J. \& Martin, N. G. (1989). Genes, Culture and Personality: an Empirical Approach. Academic Press: London.

Etter, J.-F., Duc, T. V. \& Perneger, T. V. (1999). Validity of the Fagerstrom test for nicotine dependence and of the Heaviness of Smoking Index among relatively light smokers. Addiction 94, 269-281.

Fagerström, K. O. (1978). Measuring degree of physical dependence to tobacco smoking with reference to individualization of treatment. Addictive Behaviors 3, 235-241.

Gillespie, N. A., Zhu, G., Heath, A. C., Hickie, I. B. \& Martin, N. G. (2000). The genetic aetiology of somatic distress. Psychological Medicine 30, 1051-1061.

Haddock, C. K., Lando, H., Klesges, R. C., Talcott, G. W. \& Renaud, E. A. (1999). A study of the psychometric and predictive properties of the Fagerström Test for Nicotine Dependence in a population of young smokers. Nicotine \& Tobacco Research $\mathbf{1}$ 59-66.

Han, C., McGue, M. K. \& Iacono, W. G. (1999). Lifetime tobacco, alcohol and other substance use in adolescent Minnesota twins, univariate and multivariate behavioral genetic analyses. Addiction 94, 981-993.

Heath, A. C. (1990). Persist or quit? Testing for a genetic contribution to smoking persistence. Acta Geneticae Medicae Gemellologiae 39, 447-458.

Heath, A. C., Cates, R., Martin, N. G., Meyer, J., Hewitt, J. K., Neale, M. C. \& Eaves, L. J. (1993). Genetic contribution to risk of smoking initiation: comparisons across birth cohorts and across cultures. Journal of Substance Abuse 5, 221-246.

Heath, A. C., Howells, W., Kirk, K. M., Madden, P. A. F., Bucholz, K. K., Nelson, E. C., Slutske, W. S., Statham, D. J. \& Martin, N. G. (2001). Predictors of non-response to a questionnaire survey of a volunteer twin panel: findings from the Australian 1989 twin cohort. Twin Research 4, 73-80.

Heath, A. C., Kirk, K. M., Meyer, J. M. \& Martin, N. G. (1999). Genetic and social determinants of initiation and age of onset of smoking in Australian twins. Behavior Genetics 29, 395-407.

Heath, A. C., Madden, P. A. F. \& Martin, N. G. (1998). Statistical methods in genetic research on smoking. Statistical Methods in Medical Research 7, 165-186.

Heath, A. C. \& Martin, N. G. (1993). Genetic models for the natural history of smoking, evidence for a genetic influence on smoking persistence. Addictive Behaviors 18, 19-34

Heath, A. C., Martin, N. G., Lynskey, M. T., Todorov, A. A. \& Madden, P. A. F. (2002). Estimating two-stage models for genetic influences on alcohol, tobacco or drug use initiation and dependence vulnerability in twin and family data. Twin Research $\mathbf{5}$, 113-124.

Heatherton, T. F., Kozlowski, L. T., Frecker, R. C. \& Fagerström, K.-O. (1991). The Fagerström Test for Nicotine Dependence, a revision of the Fagerström Tolerance Questionnaire. British Journal of Addiction 86, 1119-1127.

Heatherton, T. F., Kozlowski, L. T., Frecker, R. C., Rickert, W. S. \& Robinson, J. (1989). Measuring the heaviness of smoking using self-reported time to first cigarette of the day and number of cigarettes smoked per day. British Journal of Addiction 86, $1119-1127$.

Henningfield, J. E. \& Jude, N. R. (1999). Prevention of nicotine addiction, neuropsychopharmacological issues. Nicotine \& Tobacco Research 1, S41-S48.

Hettema, J. M., Corey, L. A. \& Kendler, K. S. (1999). A multivariate genetic analysis of the use of tobacco, alcohol, and caffeine in a population-based sample of male and female twins. Drug and Alcohol Dependence 57, 69-78.

Hettema, J. M., Neale, M. C. \& Kendler, K. S. (1995). Physical similarity and the equal-environment assumption in twin studies of psychiatric disorders. Behavior Genetics 25, 327-335.

Huber, P. J. (1967). The behavior of maximum likelihood estimates under non-standard conditions. Proceedings of the Fifth 
Berkeley Symposium in Mathematical Statistics and Probability, pp. 221-233. University of California Press: Berkeley, CA.

Johnson, E. O., Breslau, N. \& Anthony, J. C. (1996). The latent dimensionality of DIS/DSM-III-R nicotine dependence, exploratory analyses. Addiction 91, 583-588.

Jöreskog, K. G. \& Sörbom, D. (1995). PRELIS: A program for multivariate data screening and data summarization. A preprocessor for LISREL. Scientific Software International: Chicago, IL.

Kaprio, J., Koskenvuo, M. \& Langinvainio, H. (1984). Finnish twins reared apart IV, Smoking and drinking habits. A preliminary analysis of the effect of heredity and environment. Acta Geneticae Medicae Gemellologiae 33, 425-433.

Kendler, K. S. \& Gardner, C. O. (1998). Twin studies of adult psychiatric and substance dependence disorders: are they biased by differences in the environmental experiences of monozygotic and dizygotic twins in childhood and adolescence? Psychological Medicine 28, 625-633.

Kendler, K. S., Heath, A. C., Martin, N. G. \& Eaves, L. J. (1987). Symptoms of anxiety and symptoms of depression. Same genes, different environments? Archives of General Psychiatry 44, 451-457.

Kendler, K. S., Neale, M. C., Kessler, R. C., Heath, A. C. \& Eaves, L. J. (1993). A test of the equal-environment assumption in twin studies of psychiatric illness. Behavior Genetics 23, 21-27.

Kendler, K. S., Neale, M. C., Kessler, R. C., Heath, A. C. \& Eaves, L. J. (1994). Parental treatment and the equal environment assumption in twin studies of psychiatric illness. Psychological Medicine 24, 579-590.

Kendler, K. S., Neale, M. C., Sullivan, P., Corey, L. A., Gardner, C. O. \& Prescott, C. A. (1999). A population-based twin study in women of smoking initiation and nicotine dependence. Psychological Medicine 29, 299-308.

Kendler, K. S., Thornton, L. M. \& Pedersen, N. L. (2000). Tobacco consumption in Swedish twins reared apart and reared together. Archives of General Psychiatry 57, 886-892.

Kenny, P. J. \& Markou, A. (2001). Neurobiology of the nicotine withdrawal syndrome. Pharmacology Biochemistry and Behavior 70, 531-549.

Kobus, K. (2003). Peers and adolescent smoking. Addiction 98 (Suppl. 1), 37-55.

Koopmans, J. R., Slutske, W. S., Heath, A. C., Neale, M. C. \& Boomsma, D. I. (1999). The genetics of smoking initiation and quantity smoked in Dutch adolescent and young adult twins. Behavior Genetics 29, 383-393.

Kozlowski, L. T., Porter, C. Q., Orleans, T., Pope, M. A. \& Heatherton, T. (1994). Predicting smoking cessation with selfreported measures of nicotine dependence: FTQ, FTND, and HSI. Drug and Alcohol Dependence 34, 211-216.

LaBuda, M. C., Svikis, D. S. \& Pickens, R. W. (1997). Twin closeness and co-twin risk for substance use disorders, assessing the impact of the equal environment assumption. Psychiatry Research 70, $155-164$.

Langenbucher, J., Morgenstern, J., Labouvie, E. \& Nathan, P. E. (1994). Lifetime DSM-IV diagnosis of alcohol, cannabis, cocaine and opiate dependence, six-month reliability in a multi-site clinical sample. Addiction 89, 1115-1127.

Lichtenstein, E. \& Mermelstein, R. J. (1986). Some methodological cautions in the use of the tolerance questionnaire. Addictive Behaviors 11, 439-442.

Madden, P. A. F., Bucholz, K. K., Dinwiddie, S. H., Slutske, W. S., Bierut, L. J., Statham, D. J., Dunne, M. P., Martin, N. G. \& Heath, A. C. (1997). Nicotine withdrawal in women. Addiction 92, 889-902.

Madden, P. A. F., Heath, A. C., Pedersen, N. L., Kaprio, J., Koskenvuo, M. J. \& Martin, N. G. (1999). The genetics of smoking persistence in men and women, a multicultural study. Behavior Genetics 29, 423-431.

Maes, H. H., Woodard, C. E., Murelle, L., Meyer, J. M., Silberg, J. L., Hewitt, J. K., Rutter, M., Simonoff, E., Pickles, A., Carbonneau, R., Neale, M. C. \& Eaves, L. J. (1999). Tobacco, alcohol and drug use in eight- to sixteen-year-old twins: the
Virginia twin study of adolescent behavioral development. Journal of Studies on Alcohol 60, 293-305.

Marks, M. J., Campbell, S. M., Romm, E. \& Collins, A. C. (1991). Genotype influences the development of tolerance to nicotine in the mouse. Journal of Pharmacology \& Experimental Therapeutics 259, 392-402.

Mayhew, K. P., Flay, B. R. \& Mott, J. A. (2000). Stages in the development of adolescent smoking. Drug \& Alcohol Dependence 59 (Suppl. 1), S61-S81.

McGue, M., Elkins, I. \& Iacono, W. G. (2000). Genetic and environmental influences on adolescent substance use and abuse. American Journal of Medical Genetics 96, 671-677.

Neale, M. C., Boker, S. M., Xie, G. \& Maes, H. H. (2002). Mx. Statistical Modeling (6th edn). Virginia Commonwealth University: Richmond, VA.

Osler, M., Holst, C., Prescott, E. \& Sørensen, T. I. A. (2001). Influence of genes and family environment on adult smoking behavior assessed in an adoption study. Genetic Epidemiology 21, 193-200.

Patrick, D. L., Holst, C., Prescott, E. \& Sørensen, T. I. A. (1994). The validity of self-reported smoking, a review and meta-analysis. American Journal of Public Health 7, 1086-1093.

Pietilä, K., Lähde, T., Attila, M., Ahtee, L. \& Nordberg, A. (1998) Regulation of nicotinic receptors in the brain of mice withdrawn from chronic oral nicotine treatment. Naunyn-Schmiedeberg Archives of Pharmacology 357, 176-182.

Prescott, C. A. \& Kendler, K. S. (1995). Genetic and environmental influences on alcohol and tobacco dependence among women. NIAAA Research Monograph 30, 59-87.

Prokhorov, A. V., De Moor, C., Pallonen, U. E., Hudmon, K. S., Koehly, L. \& Hu, S. (2000). Validation of the modified Fagerstöm Tolerance Questionnaire with salivary cotinine among adolescents. Addictive Behaviors 25, 429-433.

Radzius, A., Moolchan, E. T., Henningfield, J. E., Heishman, S. J. \& Gallo, J. J. (2001). A factor analysis of the Fagerstöm Tolerance Questionnaire. Addictive Behaviors 26, 303-310.

Robins, L. N., Wing, J., Wittchen, H. U., Helzer, J. E., Babor, T. F., Burke, J., Farmer, A., Jablenski, A., Pickens, R. \& Regier, D. A. (1988). The Composite International Diagnostic Interview. An epidemiologic instrument suitable for use in conjunction with different diagnostic systems and in different cultures. Archives of General Psychiatry 45, 1069-1077.

Robinson, S. F., Marks, M. J. \& Collins, A. C. (1996). Inbred mouse strains vary in oral self-selection of nicotine. Psychopharmacology 124, 332-339.

SAS (1999). SAS/STAT User's Guide Version 8. SAS Institute Inc.: Cary, NC.

StataCorp (2001). Stata Statistical Software Release 7. Stata Corporation: College Station, TX

Stolerman, I. P. \& Jarvis, M. J. (1995). The scientific case that nicotine is addictive. Psychopharmacology 117, 2-10.

Sullivan, P. F. \& Kendler, K. S. (1999). The genetic epidemiology of smoking. Nicotine \& Tobacco Research 1 (Suppl. 2), S51-S57.

Swan, G. E. (1999). Implications of genetic epidemiology for the prevention of tobacco use. Nicotine \& Tobacco Research 1, S49-S56.

Swan, G. E., Carmelli, D. \& Cardon, L. R. (1996). The consumption of tobacco, alcohol, and coffee in Caucasian male twins: a multivariate genetic analysis. Journal of Substance Abuse 8, 19-31.

Swan, G. E., Carmelli, D. \& Cardon, L. R. (1997). Heavy consumption of cigarettes, alcohol and coffee in male twins. Journal on Studies of Alcohol 58, 182-190.

Swan, G. E., Carmelli, D., Rosenman, R. H., Fabsitz, R. R. \& Christian, J. C. (1990). Smoking and alcohol consumption in adult male twins, genetic heritability and shared environmental influences. Journal of Substance Abuse 2, 39-50.

True, W. R., Heath, A. C., Scherrer, J. F., Waterman, B., Goldberg, J., Lin, N., Eisen, S. A., Lyons, M. J. \& Tsuang, M. T. (1997). Genetic and environmental contributions to smoking. Addiction 92, 1277-1287.

True, W. R., Xian, H., Scherrer, J. F., Madden, P. A. F., Bucholz, K. K., Heath, A. C., Eisen, S. A., Lyons, M. J., Goldberg, J. \& 
Tsuang, M. (1999). Common genetic vulnerability for nicotine and alcohol dependence in men. Archives of General Psychiatry 56, 655-661.

Upadhyaya, H. P., Deas, D., Brady, K. T. \& Kruesi, M. (2002). Cigarette smoking and psychiatric comorbidity in children and adolescents. Journal of the American Academy of Child and Adolescent Psychiatry 41, 1294-1305.

USDHHS (2000). Reducing tobacco use: a report of the Surgeon General. National Center for Chronic Disease Prevention and Health Promotion, Office on Smoking and Health: Atlanta, Georgia.
White, H. (1980). A heteroskedasticity-consistent covariance matrix estimator and a direct test for heteroskedasticity. Econometrica $\mathbf{4 8}$, 817-830.

White, H. (1982). Maximum likelihood estimation of misspecified models. Econometrica 50, 1-25.

Xian, H., Scherrer, J. F., Eisen, S. A., True, W. R., Heath, A. C., Goldberg, J., Lyons, M. J. \& Tsuang, M. T. (2000). Self-reported zygosity and the equal-environments assumption for psychiatric disorders in the Vietnam era twin registry. Behavior Genetics $\mathbf{3 0}$, 303-310. 